\title{
Climate Change and Rural Female Farmers in Ghana: A Study of the Wenchi Municipality
}

Lily Yarney ${ }^{1}$, Emmanuel. K. Sakyi ${ }^{1}$, Jonathan C. Mba ${ }^{2}$ and Peter K. Achamwie ${ }^{3}$
1. Department of Public Administration and health Services Management
University of Ghana Business School; email: lyarney@ug.edu.gh
2. Association of African Universities; email: jcmba@aau.org
3. Ghana Education Service, Wenchi; email: achamwiepeter@gmail.com

\begin{abstract}
Climate change poses a major threat to development in most low and middle-income countries, especially the sub - Saharan Africa. Wurompo is a small farming community in the Wenchi Municipality of the Brong-Ahafo region of Ghana that depends on rain-fed agriculture activities for livelihood. In recent years, droughts, unpredictable rainfall pattern and crop failure have become common in the area. The study assessed knowledge and awareness, effects of climate change on female farmers, and their adaptation strategies. A case study in design, qualitative methods were used to collect data from 50 purposefully selected participants. Data were analyzed using themes and sub-themes generated from the research questions. Findings showed lack of adequate information and knowledge on climate change and its effects. Climate change has impacted negatively on these farmers stemming from decline in crop production and unavailability of adequate water supply in due season. Challenges to climate change adaptation are poverty, poor basic infrastructure, and modern farming practices. Farmers must be educated on climate change and its effects, with training on the necessary adaptation strategies to build their resilience. Policies that target rural farmers to adapt to climate change, and device modern agricultural techniques and practices are also necessary.
\end{abstract}

Keywords: Climate-change, farmers, female, Ghana, rural

\section{Introduction}

Climate change is defined by the Intergovernmental Panel on Climate Change (IPCC) as a statistically significant variation in either the mean state of the climate or in its variability or both, persisting for an extended period (typically decades or longer). Thus, climate change is explained as a long-term shift in the climatic patterns of a specific place or region measured by changes in the behavior of climatic elements such as temperature, wind patterns and precipitations resulting in changes in ecosystems and socio-economic activities [1]. Such changes according to them, bring about uncertainties in agricultural activities.

Though the fact is established that climate change is one of the of the main environmental problems of the 21 st century, most climate change stakeholders are still concerned about the political contestations, complexities and misgivings surrounding climate change [2,3,4]. Despite the lack of consensus among climate change stakeholders, authorities in the field have made it clear that intensity and frequency of extreme climate variabilities resulting in floods, cyclone, droughts, and the like are destined to rise with small mean increases in temperature $[5,6]$. The IPCC predicted the effects of these changes on humanity to be enormous and unavoidable [7, 8]. Also, Current Global Circulations Models (CGM) inability to forecast empirically, the specific levels of shifts in the planetary system, makes climate change and its impacts on humanity more worrying. Necessary and urgent steps are therefore needed to restrict these impacts for the attainment of balanced and sustained development to include poverty reduction [7].

Research has revealed that many vulnerable groups are battling with the impacts of climate change, and a lot more are yet to witness more threatening occurrences in the ensuing years [7, 9]. The IPCC sums up the problem in its 2014 report for policy makers as "Climate change will amplify existing risks and create new risks for natural and human systems. Risks are unevenly distributed and are generally greater for disadvantaged people and communities in countries at all levels of development" (page 1). Climate variability policy research therefore expect that with the limited adaptive capacity, low and middle-income countries especially, Sub-Saharan Africa 
would be unduly affected [7] Researchers argue that Sub-Saharan Africa's high susceptibility to the impacts of climate change is based on several determinants - biophysical, socio-economic, and political [7,10]. They additionally predict beyond variabilities in temperature and precipitation, the experience of intense events like floods, droughts and storms in Sub-Saharan Africa with their attendant problems on all facets of life [11, 12].

Areas south of the Sahara are likely to emerge as the most vulnerable to climate change with likely agricultural losses ranging from $2 \%$ to $7 \%$ [7]. Also, crop yield in Africa would fall by $10 \%$ to $29 \%$ by 2050 or even up to $50 \%$ as a result of climate variabilities [13]. These have serious implications for Sub-Saharan Africa considering the World Bank's projections that demand for food in this same region will double by 2030.

The agricultural sector is the backbone of the economies of most low and middle-income countries engaging about $60 \%$ of the work force and contributing close to $30 \%$ of gross domestic product (GDP) on the average in sub-Saharan Africa [14]. Smallholder farmers form the majority in the agricultural sector and are therefore the backbone of agricultural production in Africa [15]. These smallholder farmers have in their access for agricultural production, a mean of two or less hectors of land and number about 36 million across the continent $[16,17]$. Due to their dominance in the sector, they make a huge and important contribution to the domestic production of food and produce crops for export that earn foreign exchange for these economies. With reliable and consistent climatic conditions, the contributions of smallholder farmers could lead to economic stability of agriculture-dependent countries in Africa.

Ghana, like all other countries in Sub-Saharan Africa, is equally vulnerable to the impacts of Climate Change [7]. Climate change in Ghana is evidenced by extreme weather events and high unpredictability in weather patterns, and thus, impacting on people's source of livelihoods. In the last 45 years, recorded temperatures in the country rose about $1^{\circ} \mathrm{C}$ while rainfall and runoff decreased by approximately 20 and 30 percent, respectively (Ghana Meteorological Agency). Agriculture grants the largest share of Ghana's Gross Domestic Product (GDP), ranging between $35.8 \%$ and $37 \%$. It generates about $30-40 \%$ of the country's foreign exchange earnings and employs about $55 \%$ of the work force. It is predominantly practiced on smallholder, family operated farms using rudimentary technology. Hence, the effect of climate variabilities on this sector and individuals involved cannot be overemphasized. The distribution of rainfall is the single most important factor affecting agriculture in the country.

As a country that depends mainly on rain-fed agriculture, Ghana is extremely vulnerable to climate variability and change. Evidence abounds in climate change literature that farmers are aware that the climate has changed and that this change has negatively affected their output [18]. The unfortunate aspect of the climate change dilemma in Ghana is that most of the farmers do not understand or appreciate their contributions to climate change devastations. This is more so among rural farmers, especially females, who still engage in traditional forms of slash and burn systems of farming [19]. It is well acknowledged that rural women in particular play a key role in environmental and natural resource management and therefore not out of place to focus on in a study related to climate change.

There is, therefore, a clear need to investigate and learn from local climate change understandings of rural female farmers, to fill knowledge gaps, and to improve information exchange to facilitate decision-making and successful climate change adaptation strategies. It is, therefore, important to find out how farmers, who are major environmental stakeholders, perceive the issue of climate change, the type of changes they have observed in the past and how they have coped with the changes. This study was therefore conducted to unravel the level of climate change awareness, effects of climate change, and adaptation strategies among rural female farmers in Wurompo, a farming community in the Wenchi District of the Brong-Ahafo Region of Ghana.

\section{Materials and Methods}

Study Design, Area and Participants 
A case study design was employed to study the effects of climate change on rural female farmers, assess their knowledge and awareness about climate change, as well as the adaptation strategies used by these women to cope with the effects of climate change on their livelihood. The case study design was used because it offers a holistic form of inquiry [20]. The case study design granted the opportunity for an in-depth assessment and analysis of each of the objectives for the study with a view not to generalize the findings of the study, but to unveil what specifically pertains to women farmers at Wurompo in the Brong-Ahafo Region of Ghana, regarding their experiences with climate change variabilities over the years.

\section{Study Context}

The study was conducted at Wurompo, a small community that is located few kilometres from the Wenchi Municipality in the Western part of the Brong-Ahafo Region of Ghana. Wurompo is situated at the north-eastern part of Sunyani Municipality. The area is covered by moist-deciduous forest and the Guinea Savana Woodland vegetation zone [21]. The rainfall pattern is seasonal, which is a limiting factor in agriculture and plant growth. The average annual rainfall is about $1140-1270 \mathrm{~mm}$ with an average temperature of 30.9 degrees Celsius and a minimum of 21.2 degrees Celsius. The temperature of Wurompo community is generally high, averaging about 24.5 degrees Celsius, with the month of February being the hottest month, [21]. Wurompo is predominantly a farming community, and the main crops cultivated by the people are maize, yam, cassava, cowpea, with very few of them cultivating sorghum. The farmers intercrop maize, cassava, and yam, and few people in the valleys cultivate pepper, garden eggs and other vegetables. The distribution of rainfall is the single most important factor affecting agriculture in this and other parts of Ghana.

Figure 1. Map showing the study location

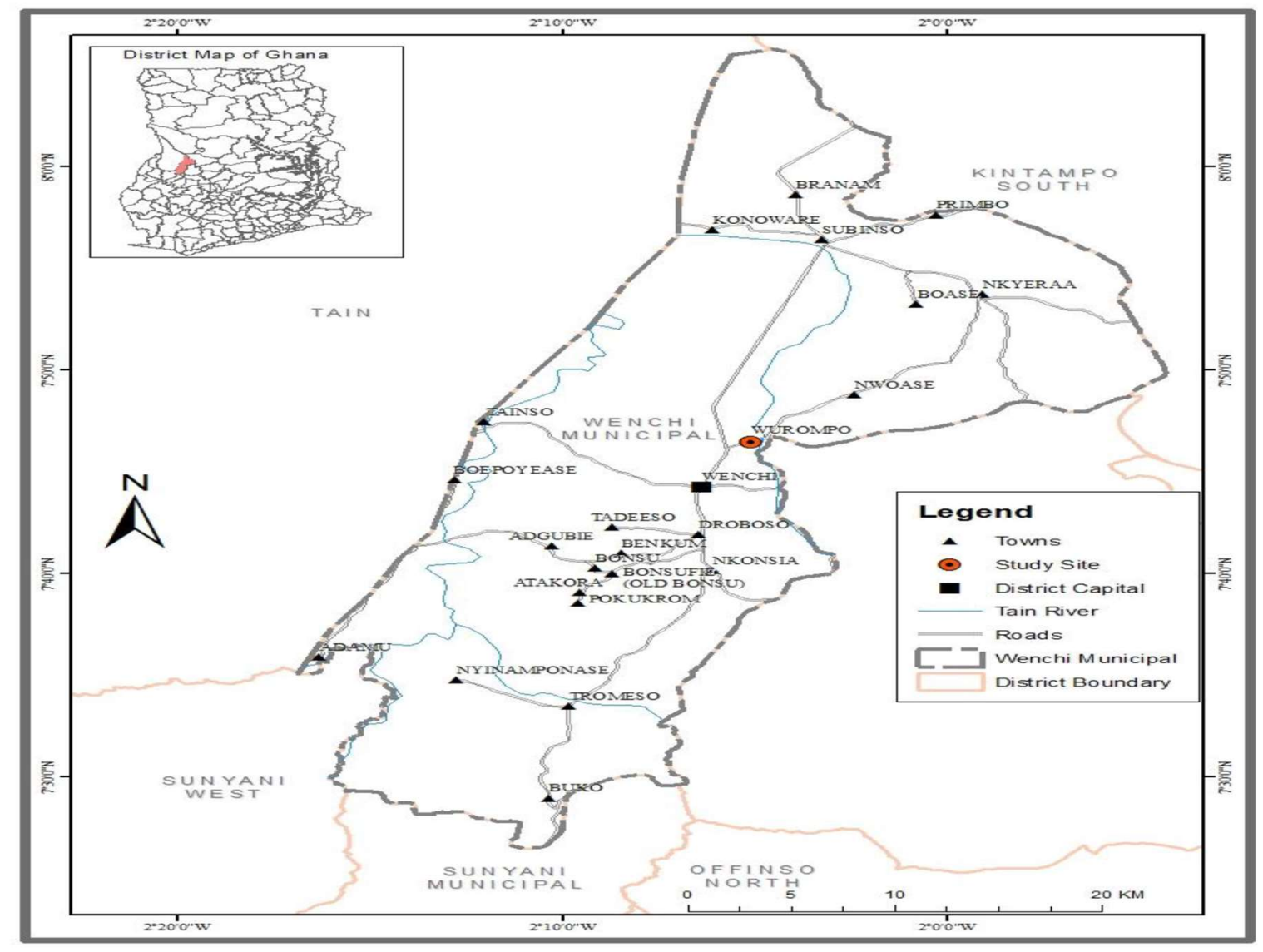

\section{Study Population, Sampling and Sample size}

Women in the Wurompo community formed the target population for the study because they are predominantly farmers and rural dwellers who have little or no formal education and are therefore relatively 
disadvantaged in terms of economic power. Thus, the negative effects of climate change may impact on them greatly. Purposive sampling technique was used to select women who were farmers in wurompo and have lived and farmed in the community for not less than five years and were willing to participate in the study. These women were in the position to narrate their experiences with climate variabilities and their coping strategies over the years. A total of 46 such women were recruited for the study. Twelve (12) of the women who had lived in the community and practiced smallholder farming activities for over 15 years were engaged in in-depth interviews whilst the remaining 34 eligible women were put in groups of 11 or 12 for focus group discussion (FGD). The participants were identified with assistance from the community leaders. Four (4) officials from the Ministry of Food and Agriculture and Ghana Meteorological Agency in the Wenchi Municipality were also selected purposively for additional information on the subject matter. A total of 50 participants took part in the study.

\section{Data Collection Methods and Instruments}

In-depth interview sessions were organized with 15 women who have experience with smallholder farming activities in the study community for over fifteen years to find out their knowledge on climate change, its effects on their farming activities and their livelihood, and how they have adapted to climate variabilities over the years. These interviews were organized individually at their convenience in the community. Additionally, the remaining 35 participants were put in 3 groups for focus group discussion. The FDGs were organized in the community to solicit spontaneous responses on the nature of climate variability occurrences in the area, knowledge, and awareness on climate change issues, how climate change has affected their normal farming practices and their livelihoods, and how they have coped with these changes. Key informants' interviews were also conducted with 4 officials from the Ministry of Agriculture and Ghana Meteorological Agency for their views on climate change impacts and adaptation in the area.

The data collection instruments consisted of in-depth interview guide, key-informants interview guide and FDG guide. These were developed by the first three authors with the research questions as guide. Data collection was led by the last author who hails from the study region and was assisted by two qualitative research experts with the requisite qualification and experience in qualitative data collection and management. All the data collectors are Master of Philosophy holders with Social Science background and are very proficient in the local Bono and Akan dialects which are the main languages in the study region.

\section{Data Management and Analysis}

All interviews and FDG discussions were recorded electronically, and manual field notes were also taken. The two qualitative research experts independently translated and transcribed verbatim all the recorded interviews and discussions verbatim into English in a word processing application and added on the manual notes taken during data collection. They then came together to review the transcripts and the original recordings and built consensus where there were disagreements. The transcripts and notes were stored as files that were coded manually for textual analysis guided by the principles of grounded theory [22]. During the coding, blocks of text were placed into nodes using themes and sub-themes. Information from the themes were compared for similar and opposing views across the transcripts on knowledge and awareness on climate change and its effects on rural women. Quotes were then selected (verbatim and enhanced slightly to improve readability) to exemplify the themes.

\section{Ethical Consideration}

Before the start of the study, ethical approval was obtained from the Ethics Committee of Humanities, University of Ghana with the study protocol. All participants were provided with written informed accent before they agreed to participate in the study. Following information and explanation on the rationale, purpose, procedures, confidentiality, participation and rights, risks, and benefits, voluntary, and right to withdrawal at any point without prejudice to participants, participants were given the opportunity choose between signing or thumbprinting the written consent form before their involvement in the study. Permission was also sought from participants to take photos and to publish the findings of the study with anonymous quotes and masked faces to make them unidentifiable. This was done by asking participants to also sign or thumbprint another portion on the written informed consent form. 


\section{Results}

The findings of the study were presented under the broad themes of demographic characteristics of participants, knowledge and awareness on climate change, effects of climate change, and adaptation strategies.

\section{Demographic characteristics of participants}

The majority (69.5\%) of the female farmers involved in the study were between the ages of 31 and 50 years, $13 \%$ were between 21 and 30 years, $8.7 \%$ were 51 to 60 years, and the remaining $8.7 \%$ were 61 years or more. About $54 \%$ of participants had primary or secondary education, and $46 \%$ had no formal education. Whilst about $35 \%$ were single (widowed or divorced), the remaining $65 \%$ were married. The majority of participants were traditional/non-religious, 39\% were Christians and 4\% were Muslim. About 46\% of the women had 5 to 20 years-experience with farming, 50\% had farmed for 21 to 40 years, and only $2(3.3 \%)$ had over 41 yearsexperience with farming (Table 1).

The 4 officials from the Ministry of Food and Agriculture and the Ghana Meteorological Agency involved in the study were all males. Their ages ranged from 36 years to 54 years, three of them were married, they all had tertiary education, and they had all worked in the Wenchi Municipality for more than 2 years.

Table 1. Socio-Demographic Characteristics of Female-Farmer Participants

\begin{tabular}{|c|c|c|}
\hline ATTRIBUTE & FREQUENCY & PERCENTAGE \\
\hline \multicolumn{3}{|l|}{ Age (Years) } \\
\hline $21-30$ & 6.0 & 13.0 \\
\hline $31-40$ & 14.0 & 30.4 \\
\hline $41-50$ & 18.0 . & 39.1 \\
\hline $51-60$ & 4.0 & 8.7 \\
\hline $61+$ & 4.0 & 8.7 \\
\hline \multicolumn{3}{|l|}{ Educational Level } \\
\hline No Formal Education & 21.0 & 45.7 \\
\hline Primary & 16.0 & 34.8 \\
\hline Secondary & 9.0 & 19.5 \\
\hline Tertiary & 0.0 & 0.0 \\
\hline \multicolumn{3}{|l|}{ Marital Status } \\
\hline Never Married Before & 0.0 & 0.0 \\
\hline Married & 30.0 & 65.2 \\
\hline Divorced & 5.0 & 10.9 \\
\hline Widowed & 11.0 & 23.9 \\
\hline \multicolumn{3}{|l|}{ Religious Affiliation } \\
\hline Christian & 18.0 & 39.1 \\
\hline Muslim & 2.0 & 4.3 \\
\hline Traditional/Non-Religious & 26.0 & 56.5 \\
\hline \multicolumn{3}{|l|}{ Years of Farming } \\
\hline $5-10$ & 10.0 & 21.7 \\
\hline $11-20$ & 11.0 & 23.9 \\
\hline $21-30$ & 17.0 & 37.0 \\
\hline $31-40$ & 6.0 & 13.0 \\
\hline $41+$ & 2.0 & 3.3 \\
\hline
\end{tabular}

\section{Knowledge and awareness on climate change}

All the female-farmer respondents were aware of changes in climatic conditions of the area. This was mainly based on their observations in changes in temperature and rainfall patterns over the years. Knowledge on climate change and its impact was, however, poor. Participants demonstrated scanty knowledge on climate change based on their experiences with the phenomenon and linked it with rising temperature and unpredictable rainfall patterns. 
Regarding sources of information on climate change, the majority indicated no information from external sources. Only a few had shallow information from few school children with limited information from local FM stations. Thus:

"The seasons nowadays, keep on changing, it used to rain in due season, but now, it even rains in the dry season. Temperatures also continue to be higher than we used to experience. These tell me that something is really happening with the weather and climate around us." (Participant, in-depth interview)

"The climate is changed in this area because there are increases in temperature over long periods of time than usual, and now we cannot differentiate between rainy and dry seasons properly, it rains anyhow during the year unexpectedly." (Participant, FGD1)

"I do not have any idea about weather changes, except that I have observed some changes. Normally, l grow my crops in the third month of the year, but it is not so now, the rainfall pattern has changed, and unstable now. Last two years, the rains started in the fourth month, but it was a different show all together last year. It started in the second month and stopped at the end of the third month and never came back until the sixth month when all our crops were destroyed." (Participant, FGD1)

“........It's my grandson who told me that he's learned from school that the climate around us keeps changing and we'll be experiencing worse conditions with regard to temperature increases with less rainfall. As to why these changes, he was unable tell." (Participant, in-depth interview) superstition.

The reasons given for the observed changes in climatic conditions ranged from 'not knowing exactly', to "......this is a difficult question, hmm, l'm not God so l cannot explain the reasons why rains are not falling as they should, and temperatures are high. However, I think that our sins are so much that God cannot bear it any longer and has decided to punish us with heat and scanty rainfall." (Participant, in-depth interview)

"l am of the view that God sometimes ceases rain from falling on our crops simply because of our evil deeds. The other day $l$ heard that a man killed his wife in the bush, and another killed a young girl for money, why won't God be annoyed when all these evil things are going on? I am saying this because, sometimes, it stops raining right after we have sown our crops." (Participant, FDG2)

Participants of FGD3 attributed low crop production mostly to poor soil fertility and the fact that they do not own land in the community. Most of the female farmers were of the view that landowners normally rent poor infertile land to them, which cannot support proper agricultural activities.

"Because we are strangers here, landowners give us portions of land that are not good. These cannot support proper agricultural activities, so we continue to remain poor because of constant low crop yield." (Participant, FDG3)

"I know the rains are not falling, but the problem is, we do not have good farmlands, that is the more reason why we are not getting enough food. Though l agree that sometimes the earth gets very hot, however, if we own good and enough farmlands, we will be able to produce more food." (Participant, FGD3)

\section{Effects of Climate Change on Female Farmers}

The unpredictable rainfall pattern, coupled with high temperatures, according to study participants, have had some effects on their lives to include poor yield, droughts, soil erosion on farmlands, wilting of crops, low and poor water resources, and failure to plant/cultivate in due season (see Figures 2, 3 and 4) 
Figure 2. Women and children fetching water from the stream and dried-up borehole.

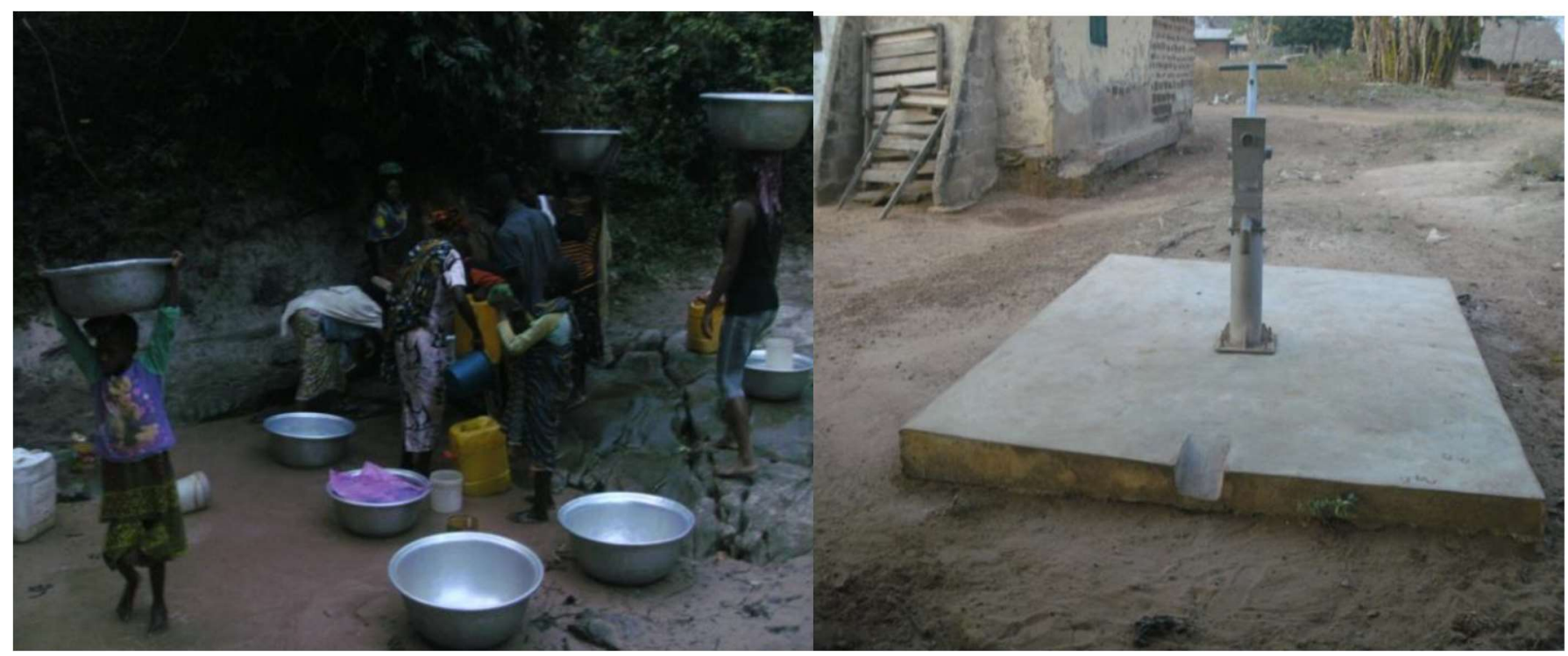

Source: Fieldwork

These have consequently impacted on their economic lives and their very existence as humans, and is witnessed as: increased poverty levels, threatened food security, increased workload of female farmers such as walking long distances in search for water, poor school performance among their daughters, migration of the $\mathrm{men} /$ husbands to cities in search for greener pastures, leading to increased burden of care of children on the women alone.

Figure 3. Destroyed pepper farm due to erosion.

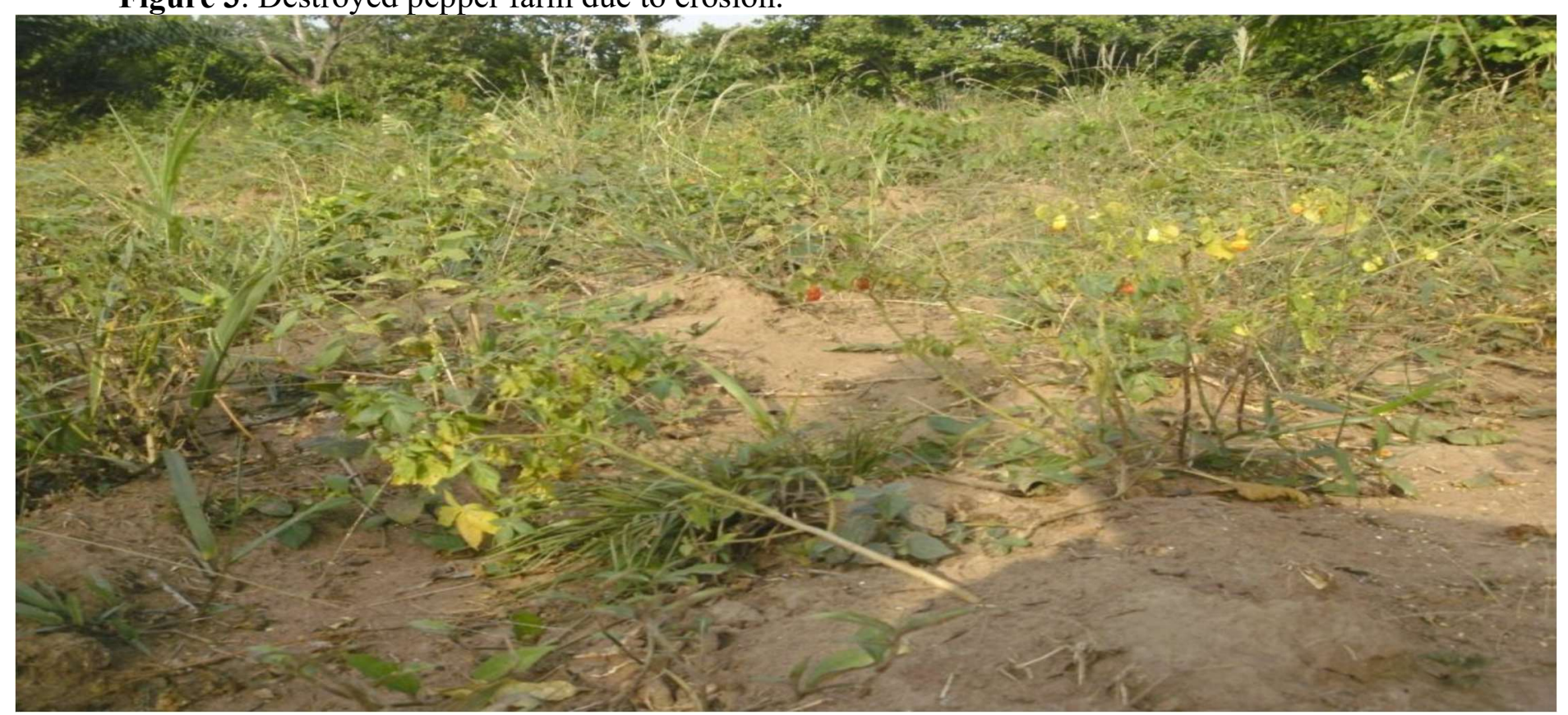

Source: Fieldwork

The female farmers noted that the unstable nature of rainfall sometimes led some people not to plant crops at all in some seasons.

Last year, for instance, most of us waited for the rains in vain, so we could not plant anything for the manor season farming. (Participant, FDG2) 
Figure 4. Poor crop yield due to low rainfall.

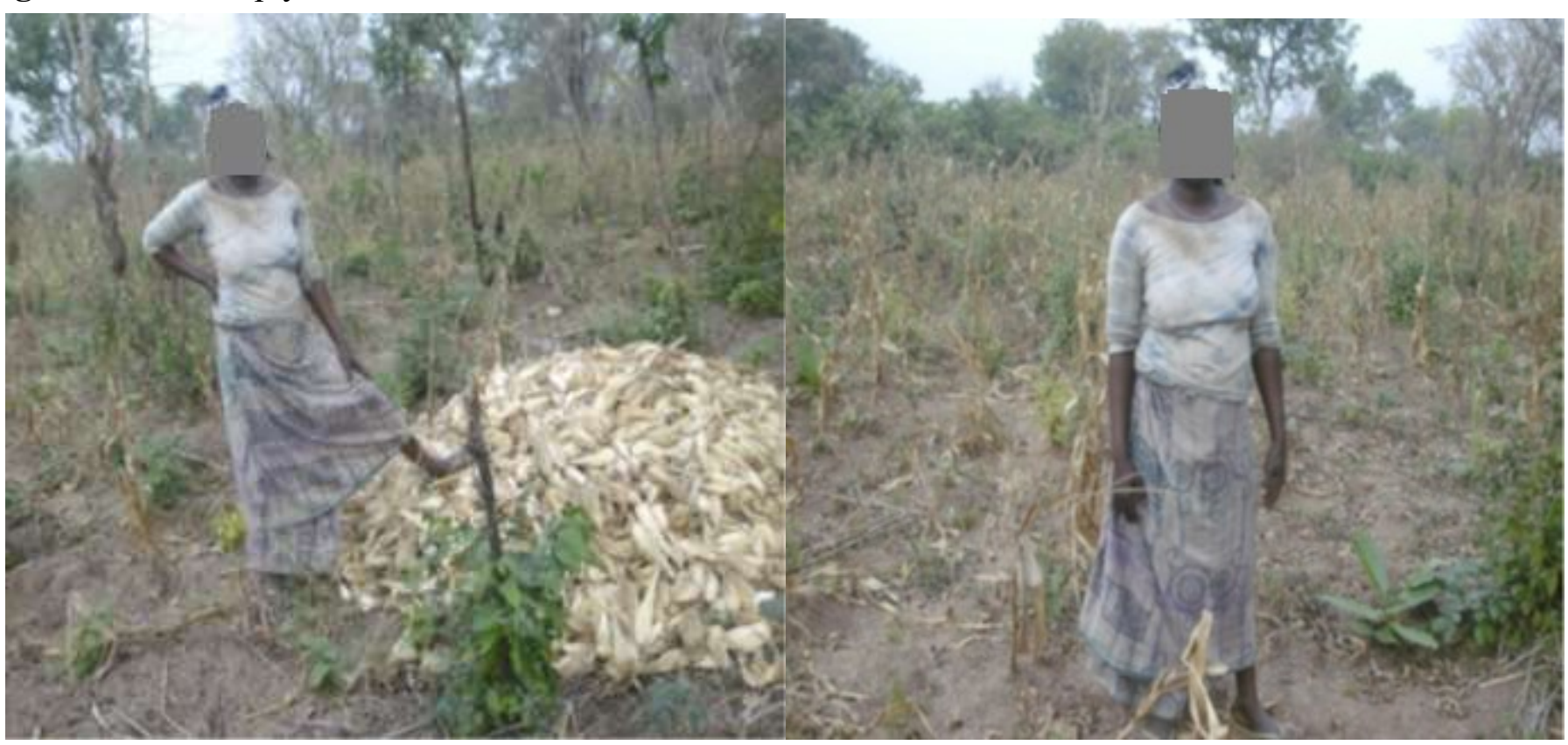

Source: Fieldwork

\section{Adaptation Strategies of Female Farmers}

Participants established that they were engaging in various activities to offset some of the effects of climate change on their lives. These include:

Planting of drought resistant and early maturing crops: A significant number of participants, especially the elderly, mostly plant drought resistant and early maturing crops like cassava, sorghum, cowpea, groundnut, beans, among others. The Dagaabas group mostly cultivate sorghum and groundnuts.

\section{Multi-cropping/mixed farming and inter-cropping:}

"I grow maize and cassava on one farm, l own cowpea farm, which is ready for harvesting, and l just finished harvesting my sorghum. The reason behind this is if some crops fail others will not. Cowpea is a good crop for some of us to plant because it matures very fast, so when it rains late, l don't cultivate any crop again apart from the cowpea and groundnuts" (Participant, FGD2)

\section{Unsustainable adaptation strategies}

Participants also declared that they engage in other social intervention activities such as:

Working on people's farms in exchange for food or money: which is popularly known among study participants as 'by day.'

".......at times I have to go and assist my friend on her farm for some small amount of money or food so I can cater to some extent for my family." (Participant, in-depth interview) 
Figure 5. Female farmers harvesting drought-resistant and early maturing crop.

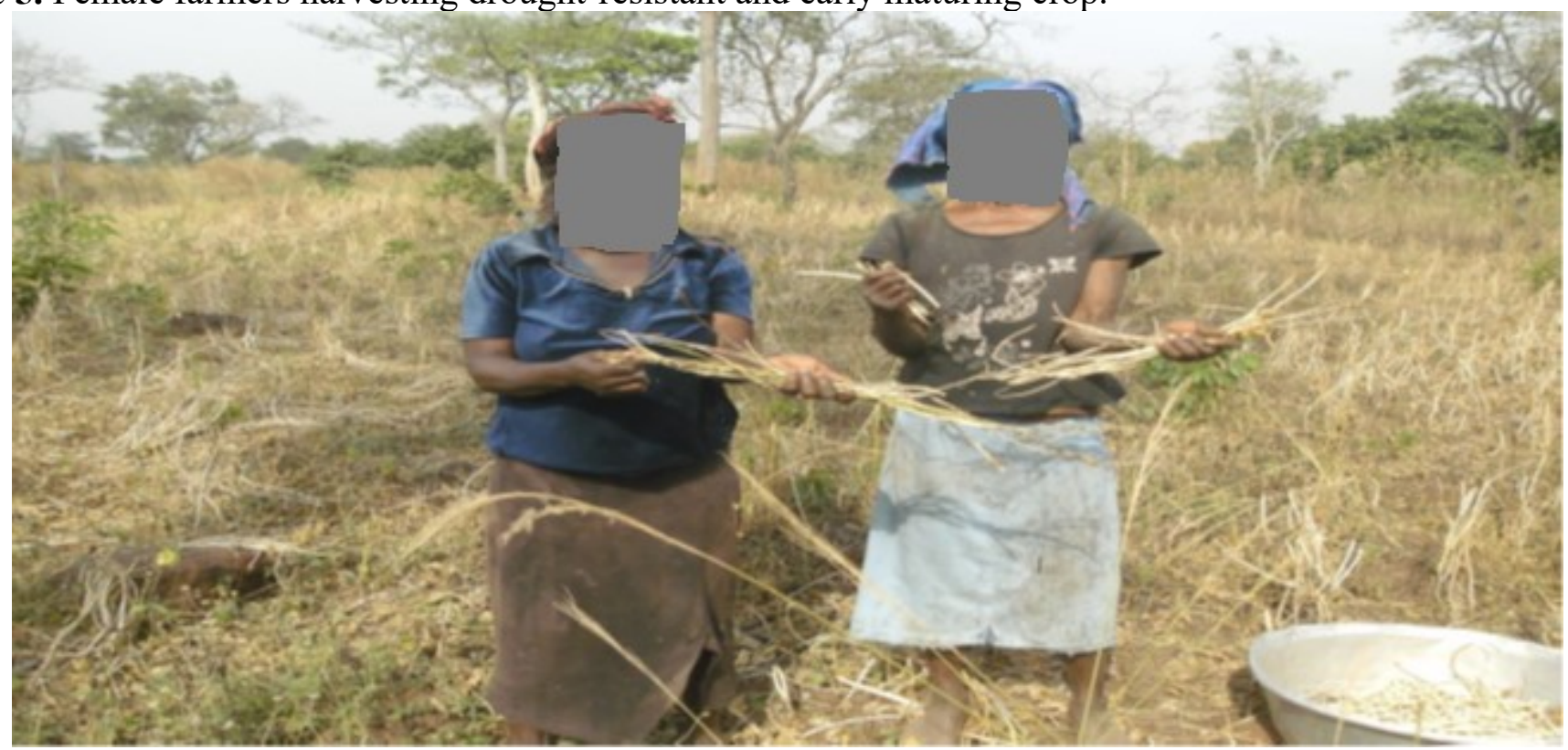

Source: Fieldwork

Migrating to other places in search of job:

Participants however, declared that though these serve to relieve them of poverty to some extent, they are not sustainable.

\section{Other maladaptation activities}

Interviews with Municipal officials revealed that farmers in the area are engaged in cutting down trees and selling of firewood, applying inorganic fertilizers to increase soil nutrient which in turn influence climate change. They also practise slash and burn method of farming with negative influence on the environment and consequential effects on the climate, as well as farming in valleys and along nearby riverbanks resulting in dry up and pollution of rivers. 
Figure 6. Tree marked to be destroyed by DDT or brine and women carrying firewood to sell at dawn.

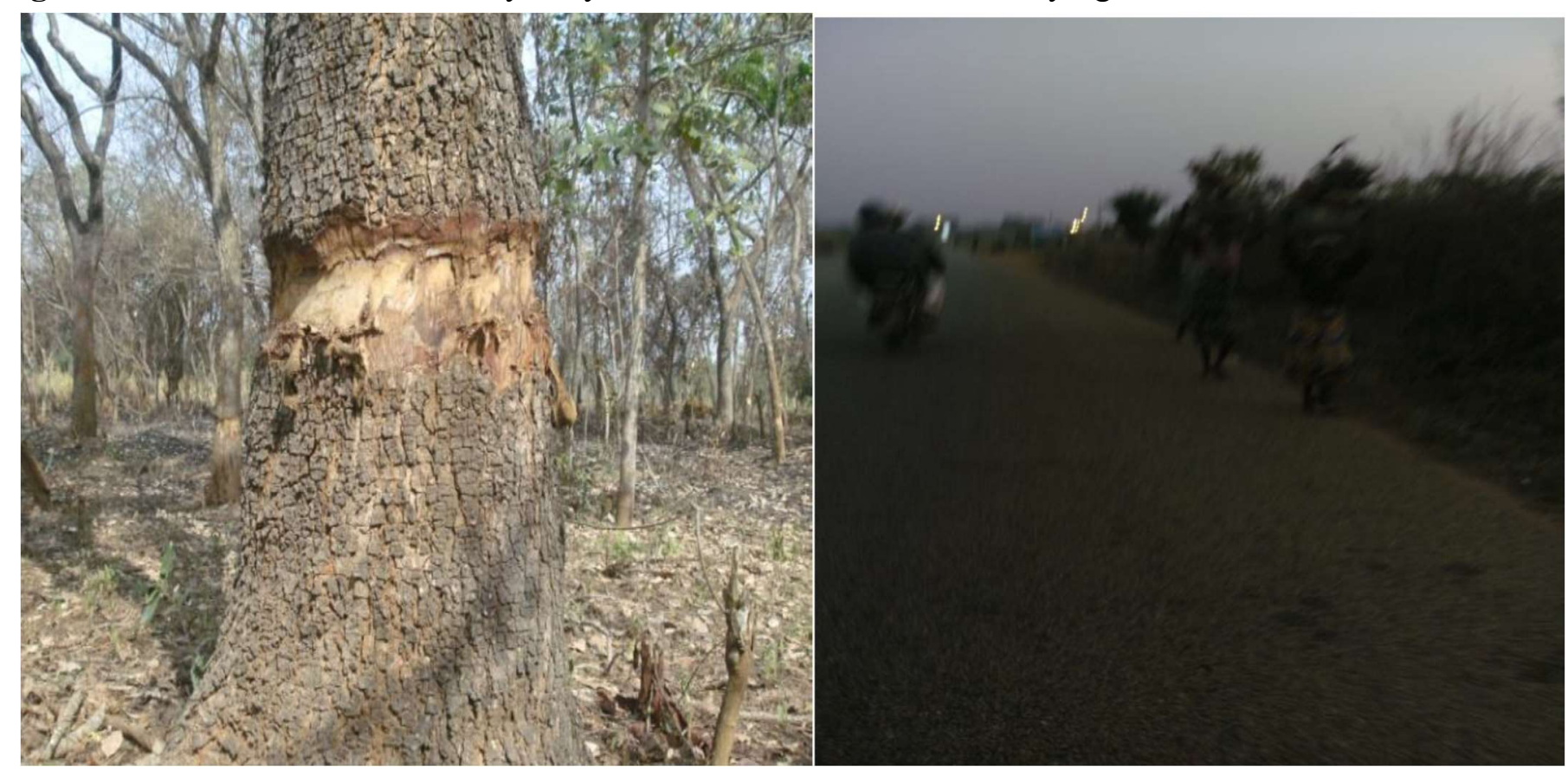

Source: Fieldwork

Figure 7. Slash and burn farming and polluted river due to nearby farming activity.

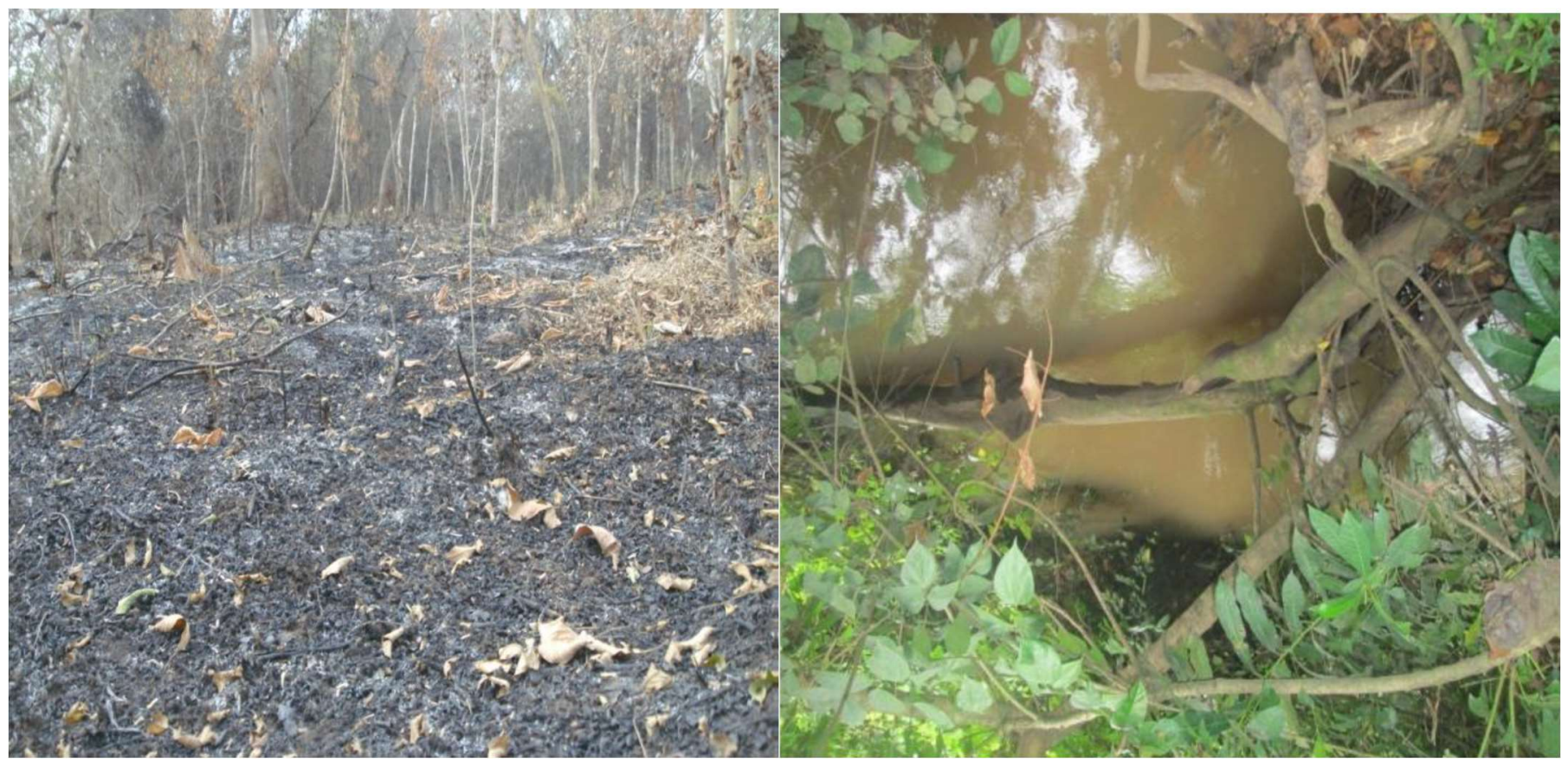

Source: Fieldwork

\section{Discussion}

The reality of climate change cannot be overemphasized, and in Ghana, the increasing variability of rainfall patterns increases the risk associated with farming as prediction becomes almost impossible. Current projections on climate indicate that rising temperatures and frequent droughts will increase the incidence of bush fires and environmental degradation [7]. Farmers in the northern part of Ghana complain of reduction in farm output arising from the uncertainty of rainfall patterns, increased erosion resulting from heavy downpour, which consequently destroys soil fertility [23]. Small-holder farmers are most vulnerable to climate change, since their margin of security is narrower. Their reliance on rain makes them more dependent on the very climate that has 
shifted and continues to shift. With less access to education and limited infrastructure and communication as the study has revealed, there are limited ways for farmers to understand the nature of the changes.

Some empirical evidence exists in Africa to suggest that some awareness and knowledge on climate change issues are present, however, these are shallow with sources of information mainly through radio and television in areas where these gadgets are found and can be afforded and just as found in the present study, experiences with differences in rainfall patterns and rising temperatures over the years. Awareness and perceptions of a problem such as climate change shapes action or inaction on the problem [24]. Consequently, understanding the perception of climate change by stakeholders, such as farmers, is important as perception can shape the preparedness of these actors to adapt and change their practices [25].

While climate change affects everyone in society, the undeniable fact is, it does not affect everyone equally. The poorest in the world, especially the developing world and particularly Africa experience it more. Women and children in Africa constitute an estimated huge number of the world's poor. Most women in Africa, and for that matter, Ghana, are always at the forefront of coping with the adverse effects of climate change because of their low economic status and the social role they play in society. In low and middle-income countries, women and girls are mostly responsible for providing basic needs such as water, fuel, and food, and in most communities in Ghana, caring for the sick is seen as their responsibility. When the resources that these women rely on for living become scarce, as in the case of rural farmers in the study due to effect of climate change, it increases their workload [26] as they are forced to struggle through alternative ventures to cope with their situation. Some of these adaptation strategies as revealed by the study are precipitating factors to climate change which eventually destroy their environment [18]. Thus, effective adaptation will require the involvement of multiple stakeholders, including policymakers, extension agents, nongovernmental organizations, researchers, communities, and farmers.

Study participants complained that the advent of climate change is affecting almost every part of their life. For instance, climate change brings about dry climate, low and erratic rainfall, and pro-longed droughts which finally affect their crops production and water resources. This also trickles down to affect their income levels, threaten their food security among other challenges. Again, the impact also increases the workload on the poor farmers and their female children. For instance, the women must walk extra miles to access water and firewood. This tends to affect girls' performance in school because they spend most of their time searching for water and other domestic products to the detriment of their education. The female farmers indicated that even though, they are already struggling with life, the advent of climate variabilities in the area is worsening their plight.

Thus, until mechanisms are carefully and systematically put in place to ensure resilience in development and reduce vulnerability, climate variability will pose serious challenges to national development. Because agricultural production remains the main source of income for most rural communities, adaptation of the agricultural sector to the adverse effects of climate change will be imperative to protect the livelihoods of the poor and to ensure food security. Adaptation can greatly reduce vulnerability to climate change by making possible consequences of climate change, people's perceptions of those consequences, and available adaptation options bare.

\section{Conclusion}

Climate change has enormous devastating impacts on rural women farmers in Ghana. The main challenges affecting these farmers' ability to cope with the current climatic problems are lack of knowledge and information about weather changes, illiteracy, and inability of some women to access and own farmlands leading to abject poverty, with its attendant economic, social, psychological, and emotional problems. Over the years, farmers and other natural resource dependent communities in the country have found varied ways of coping with these changes, based on traditional knowledge and practices. However, a better understanding of how farmers perceive climate change, ongoing adaptation measures, and the factors influencing the decision to adapt farming practices is needed to craft policies and programs aimed at promoting successful adaptation of the agricultural sector. In making informed decisions about climate change, is of the view that timely and useful information is necessary [27]

Rural female farmers must therefore be consistently educated on climate change and its effects, with training on the necessary sustainable adaptation strategies to build their resilience. Policies that target rural female 
farmers to appropriately adapt to climate change and device modern agricultural techniques and practices that boost food production among vulnerable farmers and minimize maladaptation strategies, are also necessary.

\section{Author Contributions}

Conceptualization, L.Y; Methodology: L.Y, J.C.M, Software: P.K.A; Validation: E.K.S, P.K.A; Formal Analysis: L.Y, J.C.M; Investigation: P.K.A; Data Curation: P.K.A. Writing - original draft preparation: L.Y; Writing review and editing: L.Y, E.K.S., J.C.M; Supervision: L.Y., E.K.S.

Funding: This research received no external funding.

Data Availability Statement: Data will be available upon request.

Acknowledgement: Special thanks go to Mr. Victor Dagblo in charge of crop and livestock at the ministry of food and agriculture, Wenchi municipal, for the leadership role he played in the identification of participants for the research.

Conflict of Interest: The authors declare no conflict of interest.

\section{References}

1. Urama, K.C.; Ozor, N. Impact of Climate Change on Water Resources in Africa: the Role of Adaptation. African Technology Policy Studies, 2010,1-29

2. Aylett A. "The Socio-institutional Dynamics of Urban Climate Governance: A Comparative Analysis of nnovation and Change in Durban (KZN, South Africa) and Portland (OR, USA)." Urban Studies, 2014 1386-1402

3. Mueller, V.; Gray, C.; Kosec, K., Heat stress increases long-term human migration in rural Pakistan. Nature climate change, 2014.4,182-185.

4. Ryan D., From commitment to action: A literature review on climate policy implementation at city level. Climatic Change, 2015, 131, 519-529.

5. Meehl, G.A.; Stocker, T.F.; Collins W.D., P.; Gaye A.T., Gregory J.M.,; Kitoh,A. R. Knutti, J.M. Murphy, A. Noda, S.C.B. Raper, I.G. Watterson, A.J. Weaver, Z.-C. Zhao.Global Climate Projections. In Climate Change 2007: The Physical Science Basis. Contribution of Working Group I to the Fourth Assessment Report of the Intergovernmental Panel on Climate Change. S. SolomonD. QinM. ManningZ. ChenM. MarquisK.B. AverytM. TignorH.L. Miller (eds.), Cambridge University Press, Cambridge, United Kingdom and New York, NY, USA.

6. Marks, D. "Climate change and Thailand: Impact and response." Contemporary Southeast Asia: A Journal of International and Strategic Affairs, 2011 33, 229-258.

7. IPCC (2014) Climate Change 2014: Impacts Adaptation and Vulnerability. Contributions of Working Group II to the Fourth Assessment Report of the Intergovernmental Pannel on Climate Change, 2014 Cambridge, UK: Cambridge University Press.

8. Mikulewicz, M. and Taylor, M., Getting the resilience right: climate change and development policy in the 'African Age'. New Political Economy, 2020, 25, 626-641.

9. Codjoe, S.N.A. and Atiglo, D.Y, The implications of extreme weather events for attaining the sustainable development goals in sub-Saharan Africa. Frontiers in Climate,2020, 2.

10. Connolly-Boutin, L., Smit, B., Climate change, food security, and livelihoods in sub-Saharan Africa. Regional Environmental Change, 2016. 16385-399

11. Raleigh, C., Choi, H.J., Kniveton, D. The devil is in the details: An investigation of the relationships between conflict, food price and climate across Africa. Global Environmental Change, 2015.32, 187-199.

12. Dosio, Alessandro, Hans-Jürgen Panitz, Martina Schubert-Frisius, and Daniel Lüthi. "Dynamical downscaling of CMIP5 global circulation models over CORDEX-Africa with COSMO-CLM: evaluation over the present climate and analysis of the added value." Climate Dynamics. 2015,44, 2637-2661. 
13. Jones PG, Thornton PK. Representative soil profiles for the Harmonized World Soil Database at different spatial resolutions for agricultural modelling applications. Agricultural Systems Submitted.2015.

14. World Bank, 2011. World development report: Conflict, security, and development. 2011. The World Bank.

15. Dixon, J., Tanyeri-Abur, Y., \& Wattenbach, H. "Smallholders, globalization and policy analysis". Agricultural Management, Marketing and Finance service occasional paper 5, Agricultural support systems division, 2004,FAO, Rome

16. Jaeger P. "Smallholders: How to involve small-scale farmers in commercial horticulture". A paper prepared for the 6 th video seminar in the series, High Value Agriculture in Southern and Eastern Africa, 2010, $1-20$

17. Nagayets, O. "Small Farms: Status and Key Trends". Background paper prepared for the Research Workshop on the Future of Small Farms, organized by IFPRI, Imperial College and the Overseas Development Institute, Wye, UK. 2005, 26-29

18. Enete, A.A. and Thornton, P.K. Effect of climate change and climate change mitigation. S/D, 2011.

19. Agwu, E.A., Egbule, C.L., Amadu, F.O., Morlai, T.A. Wollor, E.T. and Cegbe, L.W. What Policy Options can Promote Agricultural Innovations for Climate Change and Adaption and Food Security in the West African Sub-region? African Technology Policy Studies Network Technopolicy Brief, 2011.29

20. Creswell, JW, Creswell, JD, Research Design: Qualitative, Quantitative, and Mixed Methods Approaches. Thousand Oaks: SAGE. 2017

21. GSS (Ghana Statistical Service). "2010 Population and housing census." 2010.

22. Qualitative Research methods: a data collector's field guide. Parkdatabase; 2005. Available from: http:/www.fhi360.org/sites/default/files/media/documents/Qualitative\%20Research\%20 Methods\%20\%20A\%20Data\%20Collector's\%20Field\%20Guide.pdf

23. Aid, Action. "The time is now; Lesson from farmers to adapting to climate change." Retired from: www. actionaid. org. on August 10 (2008): 2009.

24. Nzeadibe, T.C. and Ajaero, C.K., Informal waste recycling and urban governance in Nigeria: Some experiences and policy implications. Handbook of environmental policy, 2010. 245-264.

25. Speranza, C.I.,. Drought coping and adaptation strategies: Understanding adaptations to climate change in agro-pastoral livestock production in Makueni district, Kenya. The European Journal of Development Research, 2010, 22.623-642.

26. Gonzlez, A., Belemvire, A. and Saulire, S.,. Climate Change and Women Farmers in Burkina Faso: Impact and adaptation policies and practices. Oxfam Policy and Practice: Agriculture, Food and Land, 2011, 11,108-153.

27. Olorunfemi, F.B.,. Living with waste: Major sources of worries and concerns about landfills in Lagos metropolis, Nigeria. Ethiopian journal of environmental studies and management, 2009,2. 